\begin{tabular}{|c|c|c|}
\hline & Int.J.Curr.Microbiol.App.Sci (2016) 5(10): 289-293 & \multirow{2}{*}{ 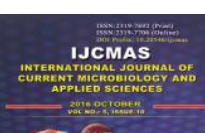 } \\
\hline & \multirow{4}{*}{$\begin{array}{l}\text { International Journal of Current Microbiology and Applied Sciences } \\
\text { ISSN: 2319-7706 Volume } 5 \text { Number } 10 \text { (2016) pp. 289-293 } \\
\text { Journal homepage: http://www.ijcmas.com }\end{array}$} & \\
\hline & & \\
\hline EXCELLENT & & \\
\hline PUBLISHERS & & wwwijijemas com \\
\hline
\end{tabular}

Original Research Article

http://dx.doi.org/10.20546/ijcmas.2016.510.032

\title{
Speciation and Antifungal Susceptibility of Candida Species Isolated from Clinical Samples - A Pilot Study
}

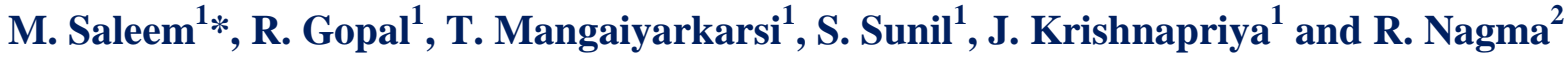 \\ ${ }^{1}$ Department of Microbiology, Sri Manakula Vinayagar Medical College and Hospital, \\ Puducherry, India \\ ${ }^{2}$ Department of Microbiology, SMVMCH, Puducherry, India \\ *Corresponding author
}

\section{A B S T R A C T}

Keywords

Candida, speciation, fluconazole, resistance, non-albicans candida species

\section{Article Info}

Accepted:

14 September 2016

Available Online:

10 October 2016
Infections due to Candida species are the most common fungal infections. The increase in the population at risk of developing invasive candidiasis viz. immunocompromised patients, patients with diabetes mellitus, prolonged use of antibiotics, immunosuppressive therapy has resulted in a rise in infections due to non-albicans candida species which are resistant to fluconazole. All candida species isolated from various clinical specimens during a period of 6 months (Jan 2016 to June 2016) were speciated by conventional tests and grown on SDA, chlamydospore agar and chrome agar. All Candida albicans isolates were tested for susceptibility to 'Fluconazole' by disc diffusion. A total of 54 specimens yielded Candida species. Non-albicans Candida species constituted the predominant isolates and the highest yield was from urine samples. Candida albicans was isolated from 20 of the 54 specimens. Only $65 \%$ of the Candida albicans were susceptible to fluconazole. Chrome agar was found to be very useful in isolation and speciation of the Candida species. Non-albicans Candida is the most common cause of candidiasis in our region. Resistance to fluconazole among Candida albicans is high $(35 \%)$.

\section{Introduction}

Candida is yeast-like fungi which are ubiquitous in nature (Edwards, 2012). The genus comprises of several hundred species, of which only a few cause disease in humans (Chander, 2012). The Candida species are commensals of the oropharynx, intestine, vagina and skin (Edwards, 2010). The incidence of candida infections has increased at an alarming rate over the past few decades (Raut et al., 2009). Candida albicans the most common species isolated from clinical specimens earlier is replaced by non-albicans species in most of the hospital based studies. The increase in the population of immunocompromised individuals due to various causes, patients with diabetes mellitus, prolonged hospital stay and antibiotic therapy, invasive 
procedures etc. have all led to the increase in the prevalence of candidiasis particularly with non-albicans species (Oliviera et al., 2006). Although all species of candida can produce invasive infections, they show considerable difference in disease severity and susceptibility to antifungal agents (Shaheen et al., 2006), hence it is necessary to identify the species to initiate appropriate antifungal agent for a better outcome.

\section{Materials and Methods}

All the candida species isolated from various clinical specimens received in the Microbiology lab during the study period of six months were speciated and susceptibility of Candida albicans to fluconazole determined. All the significant growth of candida species identified by Gram's stain from the colonies on blood agar (BA) or other routine media were subcultured on SDA with gentamycin and Hichrom candida agar (Himedia labs pvt. Ltd.) and incubated at $35^{\circ} \mathrm{c}$ for $24-48$ hours. A germ tube test was performed from the growth on SDA after reconfirming the isolate as yeast by Gram's stain and also inoculated on chlamydospore agar, urease agar and sugar fermentation and assimilation test performed as per the standard procedures.

A disk diffusion test on Mueller-Hinton agar with $2 \%$ glucose and methylene blue (Himedia labs) was performed to determine the susceptibility of the Candida albicans species isolated to fluconazole as per the criteria given in the manufacturer's product insert. The species of candida was identified based on the macro and microscopic morphology of the growth on the SDA, chlamydospore agar and Hichrom candida agar in addition to the conventional tests.

\section{Results and Discussion}

A total of 54 isolates comprising of five species of candida were isolated from the clinical specimens during the study period. Of the 54 samples maximum number of Candida species were isolated from the urine samples (81.48\%). Candida species were isolated more from the females $(61.11 \%)$ as compared to males $(20.37 \%)$. Among the 54 samples Candida non-albicans was the most common causative agent comprising of Candida glabrata (25.92\%), Candida tropicalis (16.6\%), Candida krusei (11.11\%) and Candida parapsilosis $(9.25 \%)$ whereas Candida albicans showed a distribution of $37.03 \%$. $35 \%$ of the Candida albicans species were found to be resistant to Fluconazole.

Candida species though part of the commensal flora can nevertheless produce invasive mycoses of endogenous or exogenous origin. The severity of the disease can vary widely from a localized micro-cutaneous lesion to a disseminated type of disease with varying morbidity and mortality. A host of factors including prolonged treatment with antibiotics, immunosuppressive therapy, immunosuppressive diseases like HIV, malignancy, diabetes mellitus, organ transplant recipients, invasive procedures predispose to the development of opportunistic invasive candidiasis (Tankhiwale et al., 2012). 
Table.1 Sample wise distribution of Candida albicans and non albicans species

\begin{tabular}{|c|c|c|c|c|}
\hline S. No. & Samples & $\begin{array}{c}\text { No. of } \\
\text { samples }\end{array}$ & $\begin{array}{c}\text { Candida } \\
\text { albicans }\end{array}$ & $\begin{array}{c}\text { Candida } \\
\text { non-albicans }\end{array}$ \\
\hline 1 & Urine & 44 & 18 & 26 \\
\hline 2 & Sputum & 1 & 1 & - \\
\hline 3 & Hvs & 6 & 1 & 5 \\
\hline 4 & Blood & 1 & - & 1 \\
\hline 5 & Pus & 1 & - & 1 \\
\hline 6 & Wound & 1 & - & 1 \\
\hline
\end{tabular}

Table.2 Sex wise distribution of Candida species isolated.

\begin{tabular}{|c|c|c|}
\hline Sample & Male & Female \\
\hline Urine & 11 & 33 \\
\hline Sputum & - & 1 \\
\hline HVS & - & 6 \\
\hline Blood & - & 1 \\
\hline Pus & - & 1 \\
\hline Wound & - & 1 \\
\hline Total & 11 & 43 \\
\hline
\end{tabular}

Table.3 Distribution of Candida species

\begin{tabular}{|l|c|}
\hline \multicolumn{1}{|c|}{ Species Isolated } & $\begin{array}{l}\text { No. of samples } \\
\mathrm{n}=54\end{array}$ \\
\hline Candida albicans & 20 \\
\hline Candida glabrata & 14 \\
\hline Candida tropicalis & 9 \\
\hline Candida krusei & 6 \\
\hline Candida parapsilosis & 5 \\
\hline
\end{tabular}

Table.4 susceptibility of Candida albicans to Fluconazole

\begin{tabular}{|l|l|l|}
\hline & Sensitive & Resistant \\
\hline Candida albicans $\mathrm{n}=20$ & 13 & 7 \\
\hline
\end{tabular}


Fig.1 Candida species differentiation in CHROM agar.

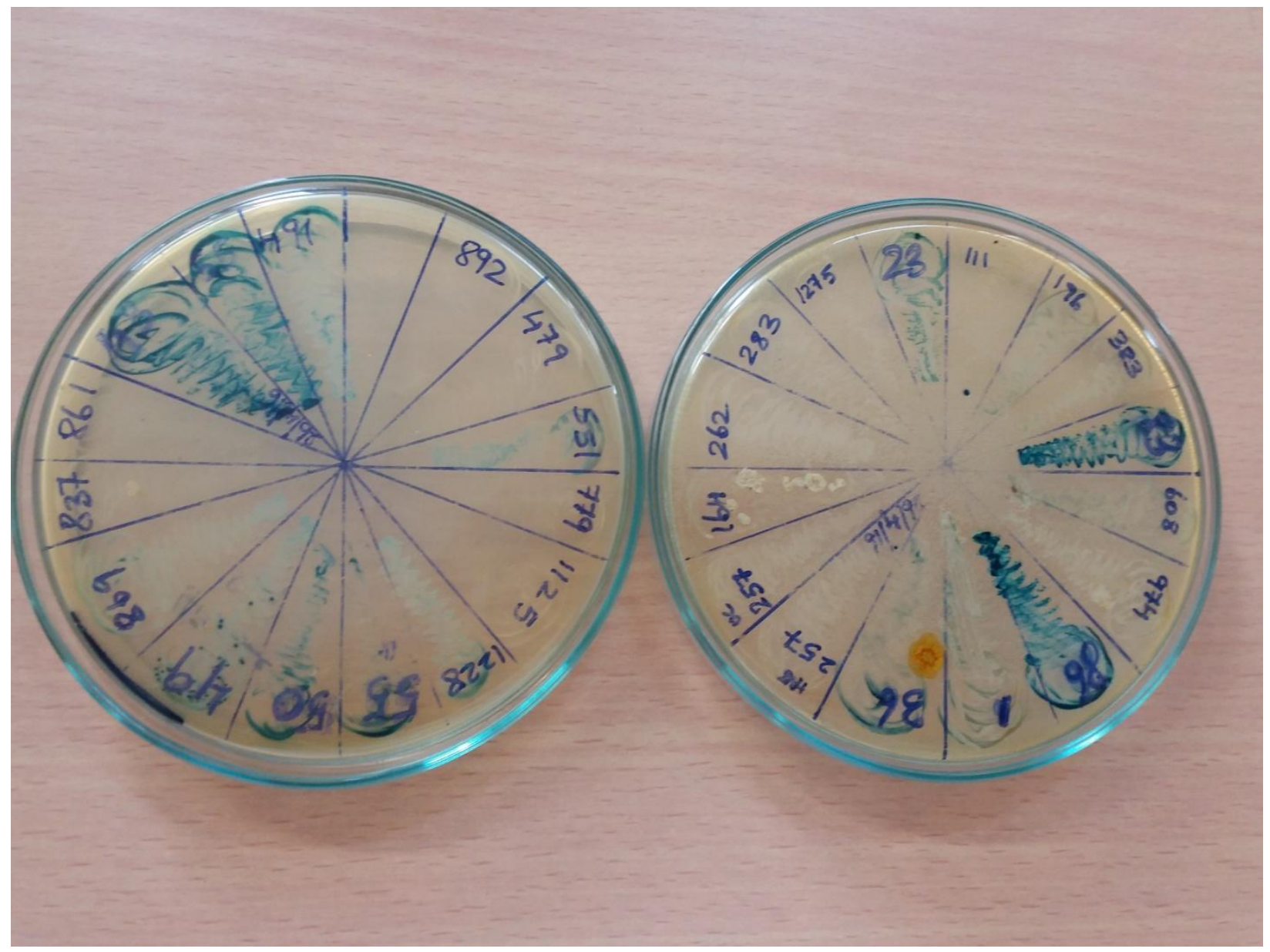

In the present study out of 54 isolates 43 (79.6\%) were from females i.e. a female preponderance which is similar to the study by Madhumati and Rajendran (Madhumati $e t$ al., 2015). The highest number of isolates (44 out of 54) were from urine. Among the urinary isolates non-albicans candida constituted 26 out of 54 while Candida albicans to 18 which is similar to the study by Madhumati (Madhumati et al., 2015), Bhaskar (Bhaskar et al., 2015) and Ravinder Sandhu (Sandhu et al., 2015). Among the candida species isolated from various specimens non-albicans candida accounted for 34 out of 54 of the total while Candida albicans to 20 out of 54 thus indicating that non-albicans candida are the predominant pathogens in our area as was the case in studies by authors. Candida glabrata constituted the predominant species among the non-albicans (14 out of 34) species. Among the Candida albicans isolates 13 out of 20 were susceptible to fluconazole $(65 \%)$ which is similar to a study by Ravinder Sandhu et al., (2015) and Bhaskar et al., (2015). There was a good correlation between conventional tests and CHROM agar for speciation.

In conclusion, the present study shows that non-albicans candida is the predominant pathogen in this region and that only $65 \%$ of Candida albicans are susceptible to fluconazole. The study also shows that the chromogenic agar is a very useful medium for isolation and species identification being 
a simple and time saving method which can be used as a routine substituting for the laborious conventional fermentation and assimilation tests. The study also shows a decrease in the susceptibility of Candida albicans to fluconazole.

\section{Acknowledgement}

We thank the institutional ethics committee for permitting us to conduct this pilot study. Conflict of interest: nil.

\section{References}

Bhaskar, U.A., Yashavanth, R., Ronald, R. 2015. Identification of Candida species from clinical samples and their antifungal susceptibility patterns. $J$. Evol. Med. Dent. Sci., 4(75): 1299813004.

Chander, J. 2012. Editor. Text book of Medical Mycology. $3^{\text {rd }}$ Ed. New Delhi: Mehta Publishers, P 266-2.

Edwards, J.E. 2010. Candida SPECIES. In: Mandell GL, Bennett JE, Dolin R, Editors. Mandell, Douglas \& Bennett's Principles and Practice of Infectious diseases. $7^{\text {th }} \quad$ Ed. Philadelphia: Churchill Livingstone, P3225-38.

Edwards, J.E. 2012. Candidiasis. In: Longo, Fauci, Kasper, Hauser, Jameson, Loscalzo, Editors. Harrison's Principles of Internal Medicine. $18^{\text {th }}$
Ed. New York: The McGraw-Hill companies, 1651-2.

Madhumati, B., Rajendran, R. 2015. "Evaluation of chrom agar in speciation of Candida species from various clinical samples in a tertiary care hospital". Int. J. Curr. Microbiol. App. Sci., 4(9): 463-72.

Oliviera, G.S., Ribiero, E.T., Baroni, F.A. 2006. An evaluation of manual and mechanical methods to identify Candida spp. from human and animal sources. Rev. Inst. Med. Trop. S Paulo, 48(6): 311-15.

Raut, S.H., Varaiya, A. 2009. Differentiation of Candida dublinenesis on Chrom Agar \& Pal's Agar. IJMM, 27(1): 5558.

Sandhu, R., Dahiya, S., Sharma, R.K. 2015. "Isolation and identification of Candida and Non albicans Candida species using chromogenic medium". Int. J. Biomed. Res., 6(12): 958-62.

Shaheen, M.A., Taha, M. 2006. Species identification of Candida isolates obtained from oral lesions of hospitalized and non-hospitalized patients with oral candidiasis. Egyptian Dermatol. Online J., 2(1).

Tankhiwale, S., Gajbhiye, S., Powar, R. 2012. Fluconazole susceptibility testing of Candida species by disk diffusion and agar dilution method. JMEDS, 1(4): 527-32.

\section{How to cite this article:}

Saleem, M., R. Gopal, T. Mangaiyarkarsi, S. Sunil, J. Krishnapriya and Nagma, R. 2016. Speciation and Antifungal Susceptibility of Candida Species Isolated from Clinical Samples A Pilot Study. Int.J.Curr.Microbiol.App.Sci. 5(10): 289-293. doi: http://dx.doi.org/10.20546/ijcmas.2016.510.032 